\title{
Abortion occurs during double fertilization and ovule development in Paeonia ludlowii
}

\author{
Tingqiao Chen ${ }^{1} \cdot$ Mengyu Xie ${ }^{1} \cdot$ Yumeng Jiang ${ }^{1} \cdot \operatorname{Tao}_{\text {Yuan }}{ }^{1} \mathbb{D}$
}

Received: 27 August 2021 / Accepted: 22 December 2021 / Published online: 20 January 2022

(c) The Author(s) 2022

\begin{abstract}
Paeonia ludlowii (Stern \& Taylor) D.Y.Hong, an endangered species, is indigenous to Tibet, China and propagated only by seed under natural conditions. Its natural reproduction is constrained by low fecundity. Excess seed abortion is a key factor restricting its natural reproduction, cultivation, introduction, and protection. Understanding the specific origin and occurrence of aborted ovules is important for the protection of offspring. Using serial sectioning analysis, we studied the process of pollination and fertilization of $P$. ludlowii and examined the characteristics of aborted ovules, developmental differences after flowering of normal and aborted ovules, and their ratios at different positions in $P$. ludlowii ovaries. During pollination, fertilization, and seed development, ovule abortion was frequent, with a random abortion position. There were three types of abortion, namely, abnormal pistil, sterile ovules, and embryo and endosperm abortions. Of these, embryo and endosperm abortions could be divided into early abortion and middle abortion. The early aborted ovules stopped growing on day 12 , the endoblast and endosperm in the embryo sac aborted gradually. Furthermore, the shape of the embryo sac cavity changed. The volume of aborted ovules was significantly different from that of fertile ovules. At ripening, the external morphology of different types of aborted seeds was significantly different. The possible reasons for the abortion of the ovules are also discussed.
\end{abstract}

Keywords Double fertilization $\cdot$ Endosperm abortion $\cdot$ Ovule $\cdot$ Seed abortion $\cdot$ Paeonia ludlowii $\cdot$ Tree peony

\section{Introduction}

Paeonia ludlowii (Stern \& Taylor) D.Y.Hong, Paeonia Sect. Moutan DC., has high ornamental, economic, breeding, medicinal, and development values (Fig. 1) (Hong 1997; Li et al. 2018; Li and Wang 2019; Lu et al. 2020, 2021; Zhang et al. 2020). Until the end of the twentieth century and the beginning of the twenty-first century, P. ludlowii was listed as an independent species (Hong 1997; Hong and Pan 2005). Wild $P$. ludlowii was only distributed in a small area in the eastern Himalayas, Tibet, China; to date, only six wild populations have been reported (Hong et al. 2017).

Tao Yuan

yuantao@bjfu.edu.cn

1 School of Landscape Architecture, National Engineering Research Center for Floriculture, Beijing Laboratory of Urban and Rural Ecological Environment, Key Laboratory of Genetics and Breeding in Forest Trees and Ornamental Plants of Ministry of Education, Beijing Key Laboratory of Ornamental Plants Germplasm Innovation and Molecular Breeding, Beijing Forestry University, Beijing 100083, People's Republic of China
All known P. ludlowii species originate from these regions (Cheng et al.1998).This species has been introduced into several areas in China, but it does not flourish in all areas; in fact, in only four areas, the species flowers and bears fruit normally (Cui et al. 2019; Li 2005; Ni 2009).

Under natural conditions, $P$. ludlowii propagates through seeds, hence, it needs to produce a large number of seeds and germinate easily to expand its population. Although $P$. ludlowii is capable of selfing and outcrossing, its rate of seed setting is only approximately $29.01 \%$, germination percentage is $2.3 \%$, and it requires approximately $2-3$ years to grow into seedlings (Hao et al. 2014; He 2008; Tang et al. 2021; Yang et al. 2007). Moreover, due to over-excavation, catastrophes, and severe anthropogenic environmental destruction, wild $P$. ludlowii is endangered in China and is listed as a second level species in the newly released list of China's national key protected wild plants (National Forestry and Grassland Administration of China 2021). Therefore, it is necessary to study seed abortion in P. ludlowii.

Seed abortion is common in most flowering plants and is considered a potentially beneficial mechanism for improving the quality of offsprings (Arathi et al. 1999; Burd 1998; Li 

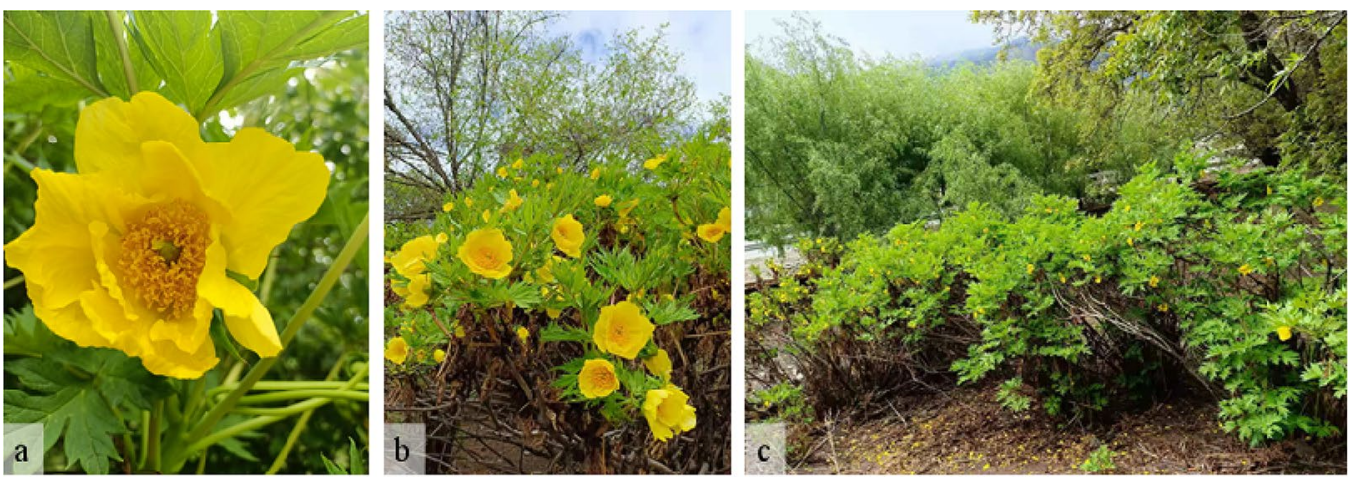

Fig. 1 Paeonia ludlowii: photo taken in Nyingchi, Tibet on May 10, 2021

et al. 2021; Meyer et al. 2014; Miyajima et al. 2003; Oneal et al. 2016; Satoki and Tomomi 2009). However, the mechanism of abortion severely restricts the proliferation, breeding, introduction, and conservation of endangered species. In fact, the phenomenon of ovule abortion in tree peonies ( $P$. suffruticosa) is common. The abortion rate of wild $P$. jishanensis could be as high as 85\% (Luo et al. 1998), and that of P. rockii is 50\% (Cheng 1996). Existing research indicates that the amount of pollen with normal development is substantial and that it could meet the demand of all ovules in each carpel. Moreover, most of the tree peony ovules develop normally (Cheng and Aoki 1999; Pan et al. 1999), but the surface structure of the stigma is primitive and simple, which is not conducive to pollination (Zhao 2002). Hence, it has been suggested that abnormal pollination, fertilization, and seed development might lead to ovule abortion in tree peonies.

A seed is the result of ovule development, and hence, to investigate seed abortion, ovule development must first be fully understood. Therefore, in this study, fluorescence microscopy and scanning electron microscopy (SEM) were used to observe the processes of pollen tube growth and fertilization to elucidate sexual reproduction in $P$. ludlowii after pollination. We also selected paraffin sections to explore the internal structure of the embryo sac before and after ovule fertilization to determine the differences between fertile and aborted ovules and the specific origin and timing of aborted ovules. We compared fertile and abortive ovules by examining the occurrence and developmental characteristics of abortive ovules and their number and positions in a mature ovary. This study provides primary data regarding the proliferation and breeding of $P$. ludlowii and lays a theoretical foundation for further studies on seed abortion.

\section{Materials and methods}

The materials used in this study were collected from the ex-situ Conservation Center of Chinese Paeoniaceae Wild Species (Little Red Village, Sanchuan Town, Luanchuan County, Luoyang City, Henan Province, China) (111 $21^{\prime}$ $36^{\prime \prime} \mathrm{E}, 33^{\circ} 56^{\prime} 05^{\prime \prime} \mathrm{N} ; 1,245 \mathrm{~m}$ altitude). Paeonia ludlowii seeds were sown in the autumn of 2002 (the seeds had been collected from a wild population). At the start of this study, the plants had been growing vigorously, and flowering and fruiting was stable, with nearly 1,500 flowers blooming every year. Light management was applied, and weeding was done once a year.

The experiment was conducted from May to September 2019 and from May to September 2020. The experiment was repeated twice for 2 consecutive years.

\section{Analysis of paraffin sections}

The carpels of $P$. ludlowii were collected before the flowers had bloomed. After collection, the stigma, style, and ovary were cut off. The styles and ovaries were placed in Carnoy's solution [95\% ethanol:glacial acetic acid (v/v), $3: 1]$. After $12 \mathrm{~h}$ of vacuum treatment, the materials were transferred to $70 \%$ ethanol solution and stored in a refrigerator at $4{ }^{\circ} \mathrm{C}$. The stigmas were then placed in a fixative [50\% ethanol:acetic acid:formaldehyde $(\mathrm{v} / \mathrm{v} / \mathrm{v})=90: 5: 5]$. After $48 \mathrm{~h}$ of vacuum treatment, the materials were washed twice in 50\% ethanol solution, each time for $2 \mathrm{~h}$, and then transferred to $70 \%$ ethanol and stored in a refrigerator at $4{ }^{\circ} \mathrm{C}$. After proper trimming, the fixed style and ovary samples were embedded in conventional paraffin sections, and the samples were sectioned using a microtome (RM2235; Leica, Germany) to a thickness of $8 \mu \mathrm{m}$. The sections were stained with hematoxylin, and permanent preparations were generated using Canada balsam. Images 
were captured under a microscope (CX40-RFL; SDPTOP, Ningbo, China).

\section{Analysis of SEM}

The fixed stigma samples were transferred to ethanol solutions of different concentrations $(70 \%, 80 \%, 90 \%, 95 \%$, and $100 \%)$ for gradient dehydration and soaked for $15 \mathrm{~min}$ at each concentration. The samples were then transferred to tertiary butyl alcohol, and subjected to cryodesiccation. The samples were then placed in an ion sputter coater and gilded for $20 \mathrm{~min}$. The stigmas were observed by SEM (S-3400N; Hitachi, Japan).

\section{Pollen tube growth}

The carpels of $P$. ludlowii were collected at $1 \mathrm{~h}, 3 \mathrm{~h}, 5 \mathrm{~h}$, $8 \mathrm{~h}, 12 \mathrm{~h}, 24 \mathrm{~h}, 36 \mathrm{~h}, 48$ h, 60 h, 72 h, 84 h, 96 h, 108 h, and $120 \mathrm{~h}$ after the flowers had bloomed. The carpel samples were fixed in Carnoy's solution [95\% ethanol:glacial acetic acid (v/v), 3:1] for $12 \mathrm{~h}$ under vacuum treatment, and then stored in $70 \%$ alcohol at $4{ }^{\circ} \mathrm{C}$ in a refrigerator.

The growth of the pollen tube through the stigma and style was observed using the aniline blue compression method (Cheng et al. 2015; Kho and Baër 1968). The collected carpel samples were dissected in the middle along the dorsal and abdominal sutures and divided into two parts. The carpel samples were then washed in distilled water and transferred into $8 \mathrm{mg} \mathrm{L}^{-1} \mathrm{NaOH}$ solution for $2 \mathrm{~h}$. Thereafter, the samples were rinsed in buffer solution of $\mathrm{pH} 6.7\left(1 \mathrm{~mol} \mathrm{~L}^{-1} \mathrm{NaOH}\right.$ solution mixed with $45 \%$ glacial acetic acid; $\mathrm{pH}$ adjusted to 6.7) for $20 \mathrm{~min}$, and then dyed with $0.1 \%$ water-soluble aniline blue dye for 6-10 h. The carpel samples were carefully taken out and spread on the slide. A drop of aniline blue solution was added, and the sample was covered with a cover glass and pressed gently. The growth of the pollen tube in the stigma and style were observed, and photographs were taken using a fluorescence microscope (DM2500; Leica).

The growth of the pollen tube in the style, ovary, and ovule was observed by section fluorescence, referring to the method of Gao et al. (2015b), with slight modifications. The specific methods were as follows. According to the pollen tube fluorescence observations in the early stage, the carpel samples after the pollen had reached the style tract were selected and then trimmed and embedded in conventional paraffin sections. After proper trimming, the fixed style and ovary samples were embedded according to the conventional paraffin section method mentioned above. The samples were sectioned using a microtome (RM2235; Leica) to a thickness of $14 \mu \mathrm{m}$. After dewaxing, the carpels were soaked in $\mathrm{pH} 6.7$ buffer for $20 \mathrm{~min}$, stained with $0.1 \%$ aniline blue solution for $2 \mathrm{~h}$, and then observed and photographed under a fluorescence microscope (DM2500; Leica).

\section{Observation of double fertilization and seed development}

The carpels at $48 \mathrm{~h}, 60 \mathrm{~h}, 72 \mathrm{~h}, 84 \mathrm{~h}, 96 \mathrm{~h}, 108 \mathrm{~h}, 120 \mathrm{~h}$, 148 h, 168 h, 8 days, 9 days, 10 days, 11 days, 12 days, 13 days, 15 days, 20 days, 25 days, 30 days, 35 days, 40 days, 45 days, 50 days, 55 days, 60 days, 65 days, 70 days, 75 days, 80 days, 90 days, and 100 days after flower blooming were collected. After proper trimming, the carpels were fixed, embedded, and sectioned, following the conventional paraffin sectioning method mentioned above (slice thickness: 9-12 $\mu \mathrm{m}$ ). The sections were stained with hematoxylin or saffron-solid green, and permanent preparations were generated using Canada balsam. Images were captured under a microscope (CX40-RFL; SDPTOP).

\section{Abortion location and abortion rate statistics}

When the seeds of $P$. ludlowii were mature, 60 fruits were randomly selected to determine the number of normal mature seeds, number of aborted seeds, and abortion location in the ovary. The aborted seeds were located in the upper, middle, and lower parts of the ovary. The lower part of the ovary was connected to the fruits, the upper part was near the stigma. The abortion rate was then calculated using Eq. 1:

$$
\begin{aligned}
& \text { Abortion rate } \\
& \qquad=\frac{\text { number of aborted seeds }}{\text { number of mature seeds }+ \text { number of aborted seeds }} \times 100
\end{aligned}
$$

Note: abortion seeds were undeveloped, flat, empty, brown, and had aborted embryos.

\section{Statistical analysis}

The rate of ovule abortion was analyzed using one-way analysis of variance with IBM SPSS Statistics (version 19.0; IBM Corp., Armonk, NY). A $P$ value of $<0.05$ indicated significant difference. There was extremely significant difference at $P$ value of $<0.01$.

\section{Results}

\section{Normal ovule fertilization and seed development}

\section{Morphological characteristics of the carpel and embryo sac:}

The carpel of $P$. ludlowii consists of three parts: stigma, style, and ovary (Fig. 2a). The plant has a wet stigma which 


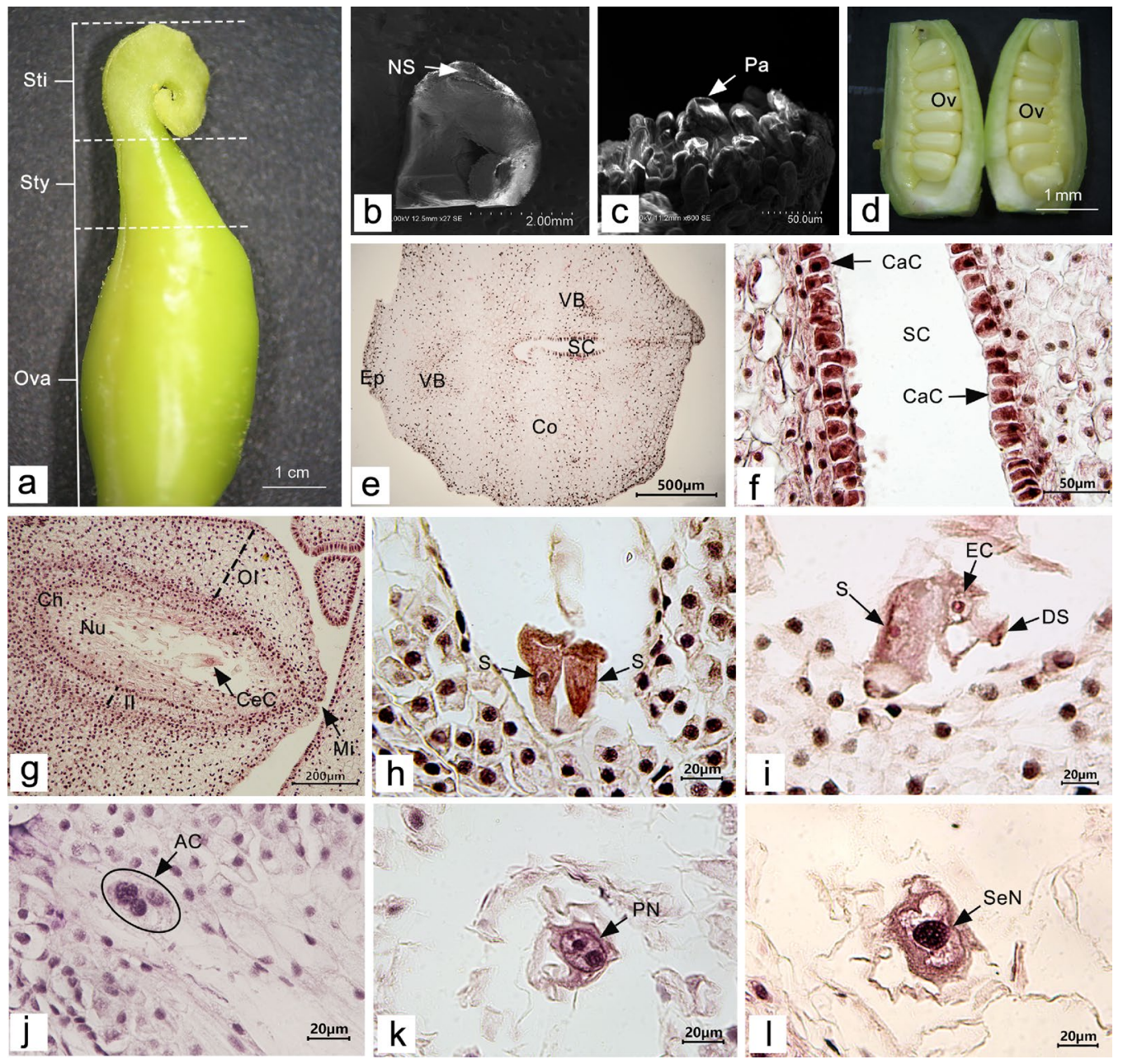

Fig. 2 Carpel and embryo sac of Paeonia ludlowii: a the carpellate form of $P$. ludlowii, consisting of the stigma, style, and ovary; $\mathbf{b}$ stigma curling nearly $360^{\circ}$ formed by two parts of similar size and shape, and creating a narrow strip in the middle (SEM); $\mathbf{c}$ the papillary cells on the surface of the stigma (SEM); $\mathbf{d}$ two rows of ovules in the ovary; e transverse section of the style, a hollow stylistic tract can be seen (Hematoxylin); $\mathbf{f}$ longitudinal section of the style, the large and distinct inner epidermal cells of the style can be clearly seen (Hematoxylin); g longitudinal section of an ovule showing the internal structure of the ovule (Hematoxylin); $\mathbf{h}$ the two synergids were located at the micropyle end, the nuclei were obvious, and there were obvious filamentous organelles at the micropyle end (Hematoxylin);

is curled in various forms, mostly about $360^{\circ}$. The stigma is formed by combining two parts of similar size and shape, and a narrow band $0.1-0.4 \mathrm{~mm}$ in width is formed in the middle (Fig. 2b). The surface of the stigma is densely covered with papillary cells (Fig. 2c). The style is joined to the stigma, and is approximately $1-3 \mathrm{~mm}$ long, with a hollow style canal in the center (Fig. 2e). The style canal is the growth channel for the pollen tube of $P$. ludlowii. The nuclei of inner canal cells of the style are large and can be clearly observed. Morphologically, these cells are regular and darker than other cells. Similar to the inner tube cells of i after flowering for $12 \mathrm{~h}$, in the egg, one synergid had degenerated (Hematoxylin); $\mathbf{j}$ the material inside the antipodal cells is intensively stained (Hematoxylin); $\mathbf{k}$ a central cell with two polar nuclei (Hematoxylin); and $\mathbf{l}$ the central cell in which the two polar nuclei fuse to form the secondary nucleus (Hematoxylin). AC, antipodal cell; $\mathrm{CeC}$, central cell; $\mathrm{CaC}$, canal cell; $\mathrm{Ch}$, chalaza; $\mathrm{Co}$, cortex; DS, degenerated synergid; EC, egg cell; Ep, epidermis; II, inner integument; Mi, micropyle; Nu, nucellus; NS, narrow strip; OI, outer integument; Ov, ovule; Ova, ovary; Pa, papilla; PN, polar nucleus; S, synergid; Sti, stigma; Sty, style; SC, style canal; VB, vascular bundle; SeN, secondary nucleus

Lilium regale (Hu et al. 1982) and Camellia oleifera (Gao et al. 2019), the inner tube cells of the style canal of P. ludlowii are glandular (Fig. 2f). Attached to the style is the ovary, in which there is a linear arrangement of two rows of inverted ovules (Fig. 2d), with a double integument, pellicle, and thick nucellus (Fig. 2g). At blooming, the embryo sac is mature and forms a typical seven-cell and eight-nucleus structure [Fig. 2h-k; Fig. 2h, two synergids; Fig. 2i, an egg cell; Fig. 2j, three antipodal cells; Fig. 2k, central cells (two polar nuclei)]. Subsequently, the two polar nuclei fuse to form a secondary nucleus (Fig. 21), but occasionally do not 
fuse to form a secondary nucleus. Only one embryo sac was observed in each ovule in all experimental materials.

\section{Pollen tube growth in the style and ovary}

The flowers of $P$. ludlowii open during the day and close at night, a feature that facilitates pollination by wind and insects. We observed that 1-12 $\mathrm{h}$ after flowering, pollen grains fell on the stigma and germinated, the pollen tube penetrated deep into the stigma, where the pollen remained
(Fig. 3a). After entering the stigma, the pollen tubes grew along the vascular bundles of the stigma and converged into the style (Fig. 3b). The tube then grew to the base through the stylistic tract and the layer of mucous secreted by the inner epidermal gland cells (Fig. 3c). After 36-48 h of flowering, the pollen tube reached the base of the style (Fig. 3d) and continued to grow toward the ovary. After penetrating the ovary, the pollen tube continued to grow along the placenta's epidermal cells (Fig. 3e). After 48-60 h of flowering, when the pollen tube approached the ovule, it was
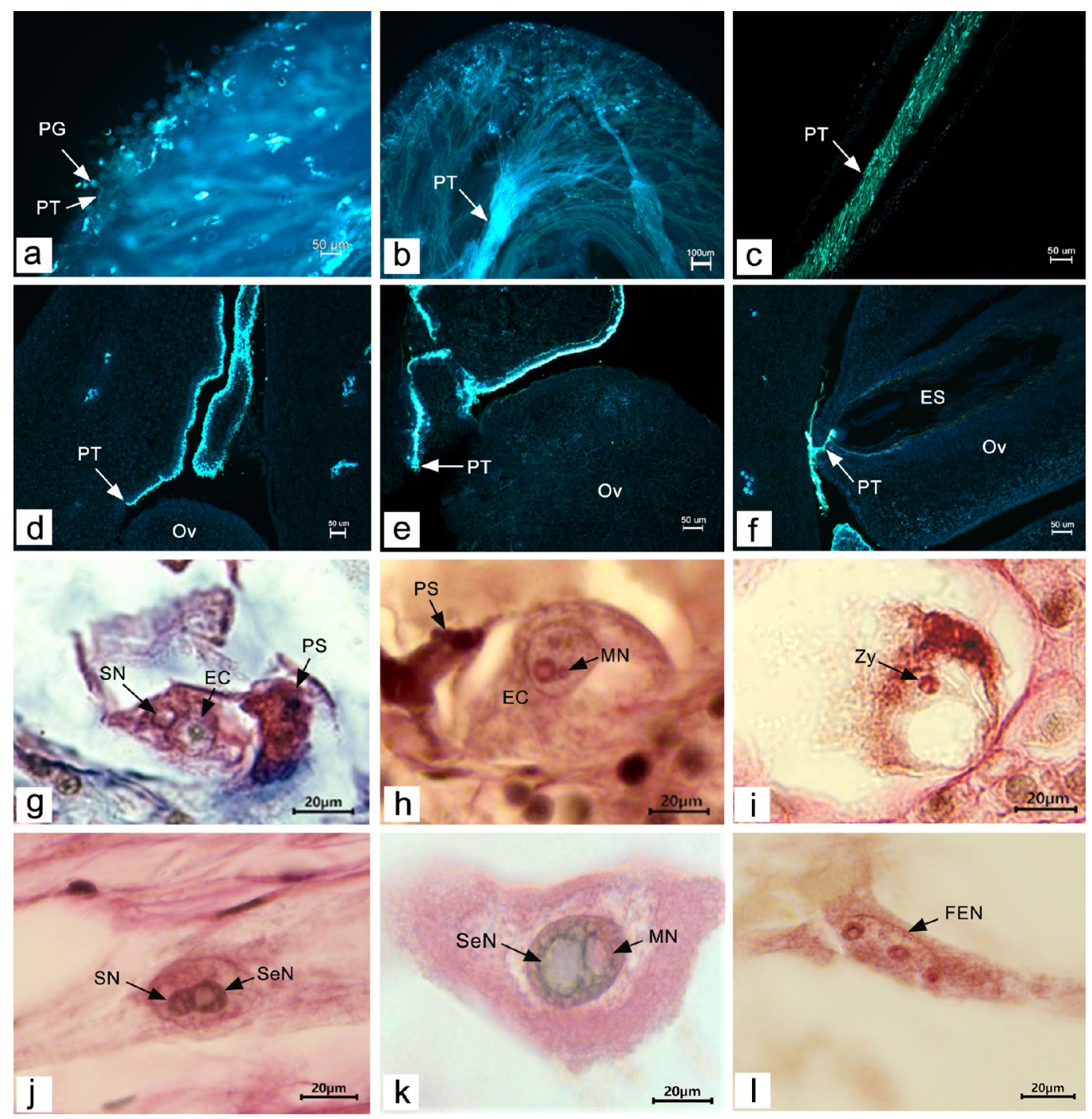

Fig. 3 Pollen tube growth and double fertilization process after natural pollination in Paeonia ludlowii: a pollen tubes germinated on the stigma and grew into the stigma (laminated fluorescence) (Aniline blue); b pollen tubes converged into the style and grew downward (laminated fluorescence) (Aniline blue); c pollen tubes grew along the stylistic tract to the ovary (section fluorescence) (Aniline blue); d the pollen tube entered the ovary along the style channel (section fluorescence) (Aniline blue); (e) pollen tube reached near the funicle of ovule along the placenta (section fluorescence) (Aniline blue); f pollen tube entered the embryo sac through the nucellus (section fluorescence) (Aniline blue); $\mathbf{g}$ the sperm nucleus attached to the egg nucleus (Hematoxylin); $\mathbf{h}$ the sperm nucleus entered the egg nucleus, showing the male nucleoli (MN) in the egg nucleus (Hematoxylin); i zygote formation (Hematoxylin); $\mathbf{j}$ the spermatic nucleus attached to the secondary nucleus (Hematoxylin); $\mathbf{k}$ male nucleoli appeared in the polar nucleus (Hematoxylin); and $\mathbf{l}$ free endosperm nucleus formation (Hematoxylin). EC, egg cell; ES, embryo sac; FEN, free endosperm nucleus; MN, male nucleus; Ov, ovule; PG, pollen grain; PT, pollen tube; PS, persistent synergid; SN, sperm nucleus; SeN, secondary nucleus; Zy, zygote 
bent nearly $90^{\circ}$ to approach and penetrate the micropyle and pass through the nucellus into the embryo sac (Fig. 3f). A few aborted pollen grains, as well as some abnormal pollen tubes and self-pollinating pollen tubes could be seen on the stigma after pollination. However, due to the large amount of pollen, sufficient pollen tubes entered the ovary, enabling us to observe each ovule in the ovary with the pollen tube entering.

\section{Double fertilization}

After passing through the apical nucellus from the degenerated synergid entering the embryo sac, the pollen tube released two sperm cells, one fusing with the egg nucleus and the other with the secondary nucleus (polar nucleus) of the central cell. The sperm nucleus gradually approached the egg nucleus, fused with it, and eventually formed the large nucleoli of the zygote completing the fertilization of the egg cell (Fig. 3g-i). This process was observed at $60-144 \mathrm{~h}$ after flowering. After zygote formation, a period of dormancy was required before the division stage. The fusion of the sperm nucleus and secondary nucleus was similar to that of the fusion of the sperm nucleus and egg nucleus (Fig. 3j, k). The difference was that the fertilization rate of the central cell was significantly higher than that of the egg cell, as determined by observing several successive sections. After fertilization of the central cell, the primary endosperm nucleus was formed; this nucleus then divided to produce the free endosperm nucleus (Fig. 31). This process was observed from $60-108 \mathrm{~h}$ after flowering. The timing of double fertilization of the ovules in each ovary was not synchronous. During 108-144 h after flowering, some ovules in the double fertilization stage were also observed, but the number was small; the process was completed by day 7 after flowering.

During the late development of fertile ovules in P. ludlowii, the primary endosperm nucleus was the first to change. After the fertilization of the secondary nucleus (polar nucleus), the primary endosperm nucleus split to form several free endosperm nuclei inside the embryo sac (Fig. 4a). Subsequently, the free endosperm nuclei were divided repeatedly, and the number of free nuclei increased continuously, during which no cell wall was formed (Fig. 4b-d). Until 45 days after flowering, the free nuclear endosperm began to cellularize, at which point the internal ovule was liquid or semi-liquid (Fig. 4e). The cellularization was completed at approximately 55 days after flowering (Fig. 4f). Thereafter, the volume of the endosperm increased rapidly; the endosperm reached its final shape and size approximately 75 days after flowering and the interior of the ovule gradually changed from liquid or semi-liquid to a solid state.

The endozygote of the fertile ovules began to divide after the end of dormancy (Fig. 4g). The zygote divided first to form the binuclear proembryo and then divided repeatedly and synchronously. The number of free nuclei increased continuously, and the proembryo grew gradually. During this period, no cell wall was formed (Fig. 4h, i). The free nuclear stage of the proembryo lasted from zygotic dormancy to 30 days after flowering. The free nuclei then began to cellularize, generally beginning at the chalazal end and advancing toward the micropylar end (Fig. 4j). At 55 days after flowering, embryo development reached the globular embryo stages (Fig. 4k, 1). Thereafter, the embryonic somatic cells divided and differentiated rapidly, and the embryonic development successively went through the heart-shaped embryo (Fig. 4m), torpedo-shaped embryo stage (Fig. 4n), and cotyledon embryo stage (Fig. 4o), until the final seeds were mature.

\section{Abnormalities during fertilization and seed development}

\section{Abnormal pistil}

During the growth and development of $P$. ludlowii, some pistils were abnormal in different ways, for example, ovule bursting, caused by the rupture of the carpel (Fig. 5a), stigma exposure before anthesis (Fig. 5c), and carpel deformity (Fig. 5b, d-f).

These abnormal pistils were present before flowering and could not be fertilized normally. Among nearly 500 flowering branches and about 1,500 open flowers (some buds failed to open normally), approximately $30 \mathrm{had}$ abnormal pistils, accounting for $0.02 \%$.

\section{Sterile ovule}

During the study, repeated experiments and many dissections showed that the appearance of carpels in the ovaries of some test materials was the same as that of other carpels, but there were sterile ovules inside. These ovules were present on the day of flowering, when the embryo sac matured, rather than being abnormal during post-pollination development. These ovules were markedly different from other ovules in morphology; that is, they were smaller in size or deformed (Fig. $5 \mathrm{~g}-\mathrm{i}$ ). Some had no embryo sac, and there were no clear spaces between the outer and inner integument (Fig. 5j, m). Moreover, some of the ovules had embryo sac structures, and the space was small, without any obvious organizational structure (Fig. 5k, 1, n, o). In the materials observed, not all carpels had sterile ovules, and according to the statistics, the carpels with sterile ovules accounted for $10.59-15.73 \%$ of all the test materials.

In addition, through several sections and repeated experiments, we found some abnormal embryo sacs in the experimental materials during fertilization. The main 


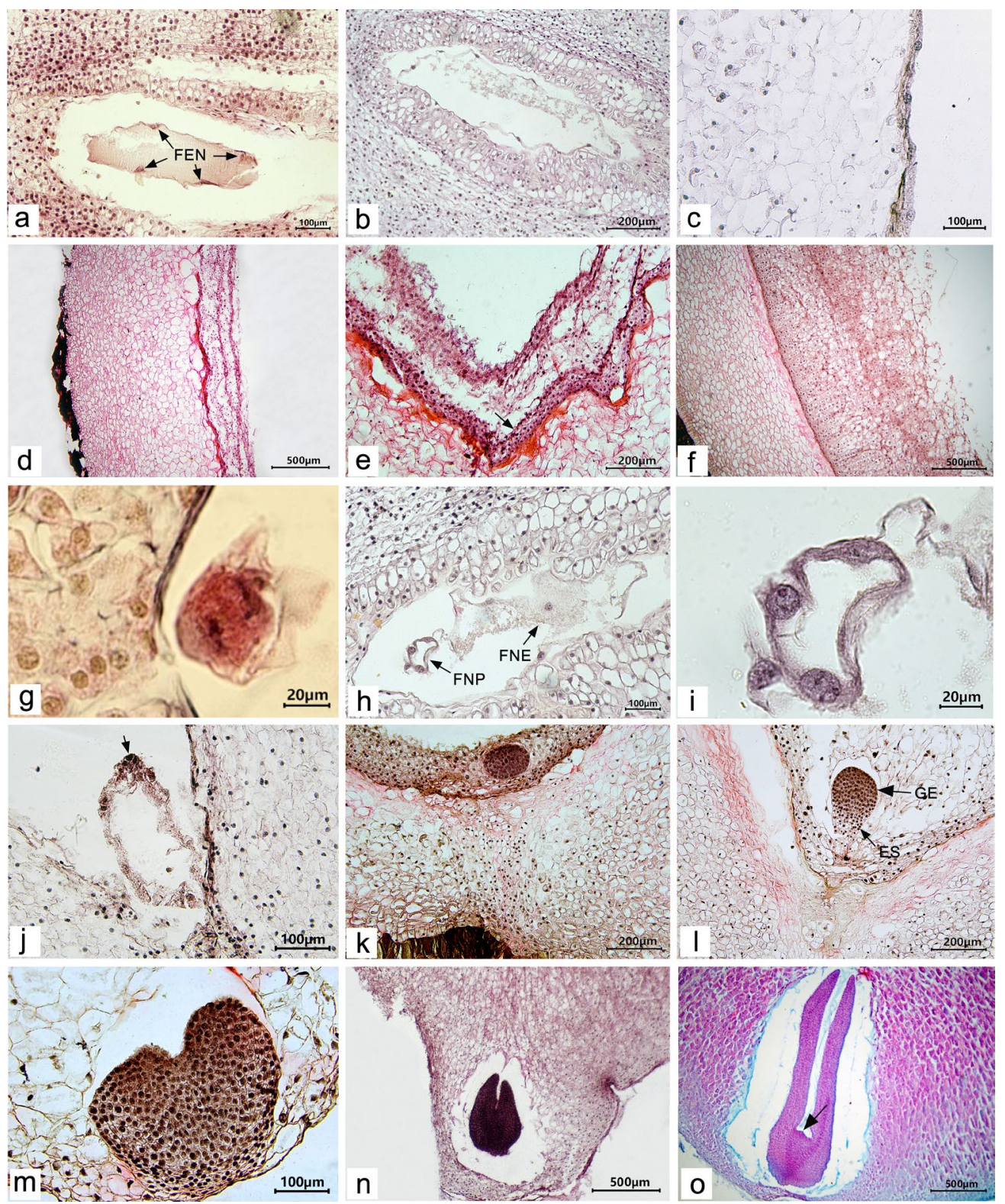

Fig. 4 Development of the endosperm and embryo in a fertile ovule of Paeonia ludlowii: a-c at 120 h, 12 days, and 20 days after flowering, the free nuclei of the embryo sac and endosperm continued to divide, the nucellus and inner tegmentum degenerated, and the endosperm adjoined the outer tegmentum (Hematoxylin); $\mathbf{d}$ the free nuclei of the endosperm continued to divide, the degraded area of the pearly layer was formed (40 days after flowering) (Hematoxylin); e 45 days after flowering, the endosperm began to cellularize (arrow shows the cellularized endosperm) (Hematoxylin); f 55 days after flowering, the endosperm was cellularized (Hematoxylin); g telophase of the first zygote division (108 $\mathrm{h}$ after flowering) (Hematoxylin); $\mathbf{h}, \mathbf{i}$ the embryo sac of free nuclear proembryo and free nuclear

characteristics of these abnormal embryo sacs were as follows. (1) At $84 \mathrm{~h}$ after anthesis, the pollen tube had reached the ovary, and most ovules had begun fertilization, but the two synergistic cells in the individual embryo sac remained endosperm (12 days after flowering), $\mathbf{i}$ the amplification of free nuclear proembryo in $\mathbf{h}$ (arrow shows free nuclei) (Hematoxylin); $\mathbf{j}$ the free nuclei at the chalazal end began to cellularize (30 days after flowering) (arrow shows the cellularized embryo) (Hematoxylin); $\mathbf{k}$ early stage of spherical embryo (55 days after flowering) (Hematoxylin); 1 late globular embryo (60 days after flowering) (Hematoxylin); m heart-shaped embryo (65 days after flowering) (Hematoxylin); $\mathbf{n}$ torpedo embryo (70 days after flowering) (Hematoxylin); o cotyledons at seed maturity (arrow indicates points of growth) (100 days after flowering) (Hematoxylin). FNN, free nuclear endosperm; FNP, free nuclear proembryo; GE, globular embryo; ES, embryo stalk

intact without degeneration. The embryo sac, which could not enter the physiological state of fertilization in time, could not be fertilized normally (Cheng 1996). (2) At 8-12 days after flowering, free nuclear proembryo and endosperm were 

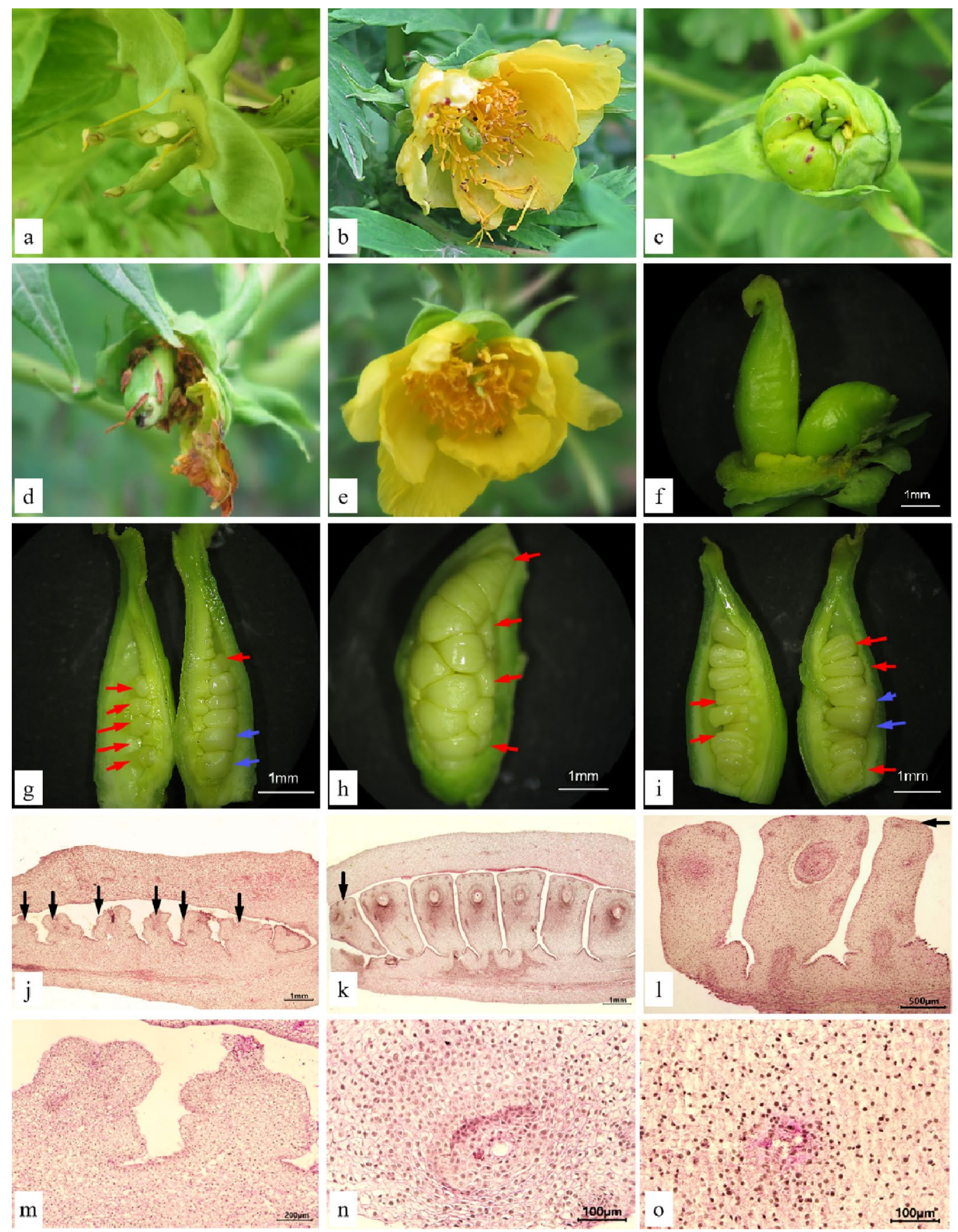

Fig. 5 Abnormal pistils and sterile ovules of Paeonia ludlowii: a a ruptured ovary; the ovules are protruding; b stigma; c abnormally curved carpel; $\mathbf{d}$ abnormal style and stigma; $\mathbf{e}, \mathbf{f}$ one carpel of flower without stigma or with a regressed stigma; $\mathbf{g}-\mathbf{i}$ sterile ovules at different position in the ovary (sterile and fertile ovules are indicated

formed in the fertilized ovules, and the number of free nuclei increased significantly, but the secondary nuclei in some of the embryo sacs remained unfertilized, and no endosperm free nuclei were formed. These ovules could not develop into by red and blue arrows, respectively); $\mathbf{j}-\mathbf{0}$ microstructure of abortive ovules in the ovary (Hematoxylin), $\mathbf{j}, \mathbf{m}$ the whole row of ovules in the ovary were aborted (on the first day of flowering), $\mathbf{k}, \mathbf{n}$ ovules in a row that were aborted in the upper position of the ovary, and $\mathbf{l}, \mathbf{o}$ ovule abortion in the middle position

seeds normally without double fertilization. The ovules containing abnormal embryo sacs accounted for approximately $1.2 \%$ of all experimental materials, and only a few carpels had abnormal embryo sacs. 


\section{Degeneration of the embryo and endosperm}

There were some ovules in the carpel, which could complete double fertilization and showed zygote and primary endosperm nuclear division in the early stages but could not develop further in the late stages. At 9 days after flowering, some aborted ovules similar in size to normal ovules showed abnormalities in the embryo sac and degeneretion of the free nuclei of the endosperm (Fig. 6a, b). On day 10 after flowering, the free nuclei of the endosperm continued to degenerate (Fig. 6c). Some abortive ovules of the same size as normal ovules showed shrinkage and deformity in their outer tepals after dewatering and embedding (Fig. 6d). When no free nuclear embryo was observed in the embryo sac, the endosperm developed abnormally, and the free endosperm nuclei were rare and irregular. The cytoplasm of the endosperm gradually disintegrated and was in a state of severe degeneration (Fig. 6e, f). In the material at 11 days after flowering, apart from the phenomenon of endosperm abortion, the free endosperms in some of the embryo sacs aggregated after nuclear division but did not separate (Fig. 6g). At 12 days after flowering, the endosperm of the fertilized ovules degenerated. In some embryo sacs, only the free nuclear proembryo developed to the stage of dinucleus proembryo, but the free endosperm nuclei were rare, the cytoplasm was significantly reduced, and the embryo sac was in a severely degenerated state; consequently, the embryo sac became narrow (Fig. 6h). Embryo sacs were
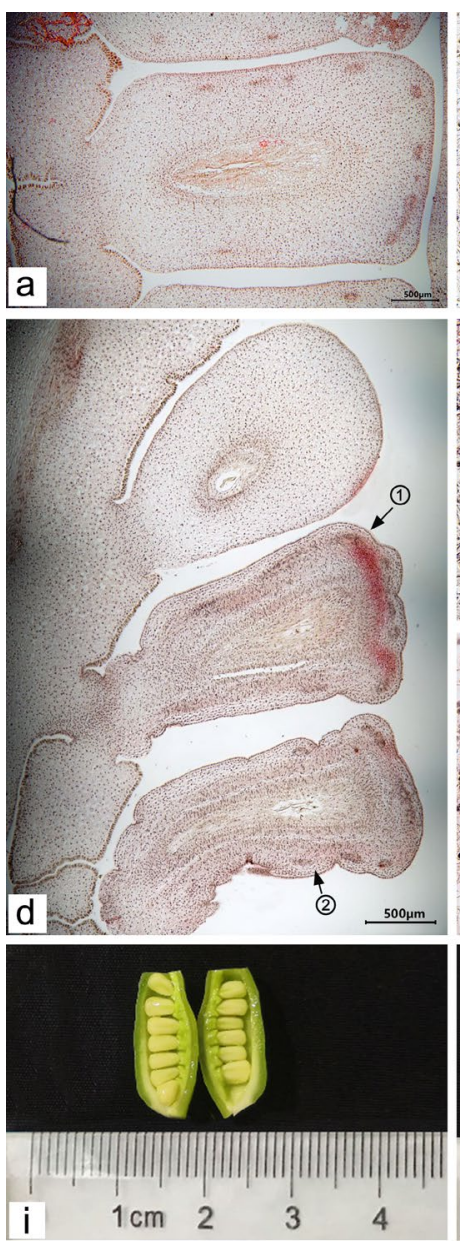

Fig. 6 Degradation of embryo and endosperm after double fertilization of aborted ovules in Paeonia ludlowii: $\mathbf{a}, \mathbf{b}$ the endosperm in the embryo sac was degenerative. The cavity of the embryo sac became narrow 9 days after flowering (Hematoxylin); c aborted ovules at 10 days after flowering (Hematoxylin); d-f two successive aborted ovules (10 days after flowering) (Hematoxylin), e enlargement of the embryo sac in d-1, $\mathbf{f}$ enlargement of the embryo sac in d-(2), the cytoplasm of the endosperm was reduced, and most of the free nuclei had degenerated; $\mathbf{g}$ there was free endosperm nuclear division, but no
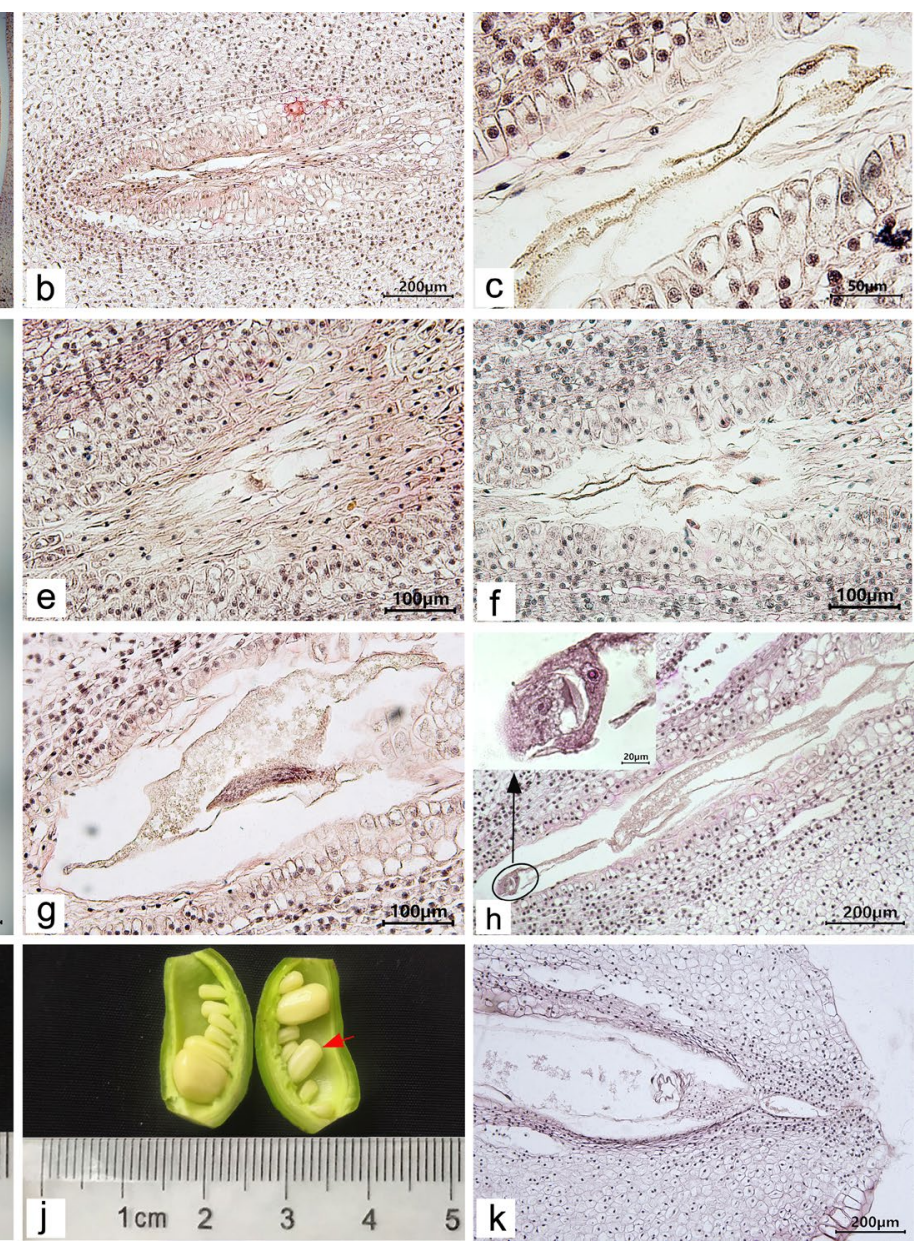

separation (11 days after flowering) (Hematoxylin); $\mathbf{h}$ the embryo in the embryo sac was in the dikaryotic proembryo stage, but the free nucleus of the endosperm had degenerated, only a part of the cytoplasm remained, and the embryo sac became small (12 days after flowering); $\mathbf{i}$ at 12 days after flowering, the ovules volume in the ovaries was different (Hematoxylin); $\mathbf{j}, \mathbf{k}$ at 20 days after flowering, some of normally developing ovules in the early stage were aborted, $\mathbf{k}$ the internal structure of the embryo sac shown with the red arrow in $\mathbf{j}$ (Hematoxylin) 
distinct from the fertile ovules at the same period (Fig. 4h). On the same day, with the development of the ovaries and the enlargement of the ovules, the ovules' volume in the ovaries began to show differences (Fig. 6i). A few aborted ovules developed normally until approximately 20 days after flowering, and the volume of the ovules was slightly larger than that of other early aborted ovules and slightly smaller than that of fertile ovules (Fig. 6j, indicated with red arrows). The free nuclei of the embryo and endosperm in these aborted ovules were not as developed as the other fertile ovules and tended to degenerate (Fig. 6k). At this time, less than one-third of the fertile ovules were observed in the ovary, and abortive ovules were observed in all carpels. The results indicated that the abortion of embryo and endosperm occurred mainly in the early stage, $9-12$ days after flowering.

\section{Late development of abortive ovules}

After 12 days, the embryo sacs of some aborted ovules gradually contracted toward the nucellus, the cavity of the embryo sac became narrow and long, degenerated, and necrotic, and filled with a brown material (Fig. 7a, b). At 30 days after flowering, the embryo, nucellar, and integument gradually degenerated (Fig. 7c). Some embryo sacs were filled with large cells, with only a narrow gap in the middle, with darker staining (Fig. 7d-g). With the growth of the ovule, the free nuclear embryo and endosperm of
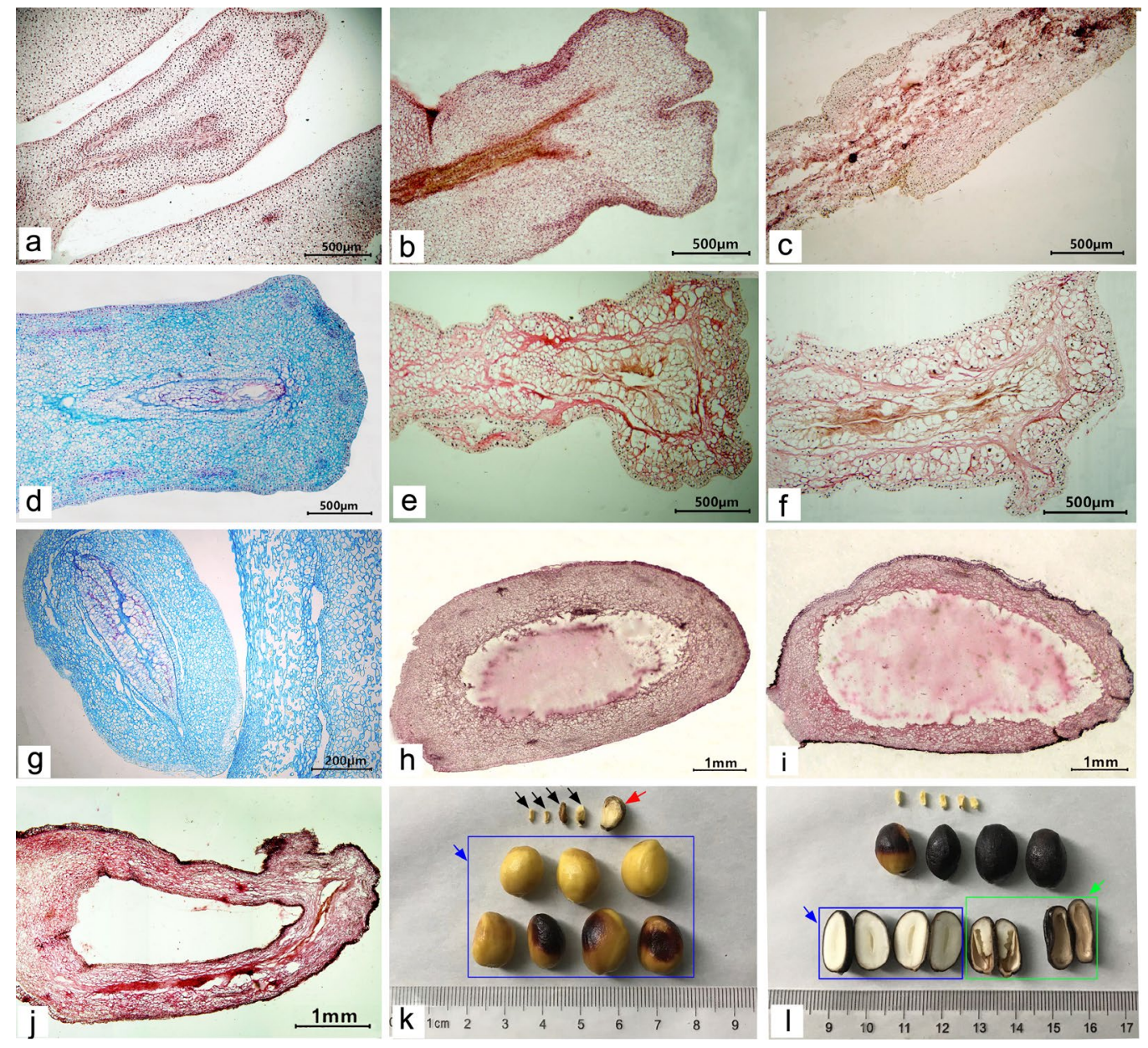

Fig. 7 Late development of aborted ovules: a-d the development of aborted ovules at 12, 25, 30, and 35 days after flowering a-c were stained with hematoxylin and $\mathbf{d}$ was stained with saffron-solid green); $\mathbf{e}, \mathbf{f}$ development of aborted ovules at 55 days after flowering (Hematoxylin); $\mathbf{g}$ development of aborted ovules at 70 days after flowering (saffron-solid green); $\mathbf{h}-\mathbf{j}$ development of the aborted ovules of free nuclear embryos and endosperm aborted at 20 days after flowering at 30, 45, and 70 days after flowering, respectively (Hematoxylin); $\mathbf{k}$ comparison of fertile ovules and aborted ovules at seed harvest (normal seeds are indicated with the blue arrow, the early aborted seeds at 9-12 days after flowering are indicated with the black arrows, and the medium-term aborted ovules at 20 days after flowering are indicated with the red arrow), and $\mathbf{l}$ comparison of the internal structure of aborted ovules and fertile ovules at seed harvest (normal seeds are indicated with the blue arrow, and the late abortive seeds are indicated with the green arrow) 
some ovules that began to abort at approximately 20 days after flowering degenerated completely, and the outer envelope had also gradually degenerated, finally forming a hollow shell with no embryo or endosperm in the embryo sac. The outer cover gradually degenerated, finally forming a hollow shell without an embryo and endosperm in the embryo sac (Fig. $7 \mathrm{~h}-\mathrm{j}$ ). Although the embryo and endosperm were not formed in the aborted ovules, the external morphology of the aborted seeds significantly differed (Fig. 7k, indicated with the red arrow). In addition, when harvesting seeds, we also found a few seeds with external morphology and volume similar to those of the fertile seeds, but they were deformed after applying pressure. After peeling, the seeds were hollow inside, without embryo or endosperm structure (Fig. 71, indicated with the green arrow). This could be attributed to embryo and endosperm atrophy during seed maturity.

\section{Position and rate of aborted ovules in P. ludlowii}

The total number of seeds in a single carpel ranged from $6-23$, and the number of normal seeds ranged from $0-8$ (2-4 more). More than two-thirds of the ovules were aborted (Table 1, Fig. 8). According to the statistics of the rate of abortion seeds (Table 1), the seed abortion rate in the ovaries in 2019 and 2020 was $69.14 \%$ and $74.01 \%$, respectively, and the abortion rate in wild populations was also high $(66.39 \%)$, indicating that seed abortion occurred independent of the growing environment.

The statistical results of the position of aborted seeds in P. ludlowii (Table 1) showed that, in 2019, the abortion rate in the lower part of the ovary was the highest (77.08\%) and the abortion rates in the middle and upper parts of the ovary were $66.98 \%$ and $66.25 \%$, respectively. Moreover, the differences among the three parts were significant. In 2020,

Table 1 Ovule position and abortion rate in Paeonia ludlowii

\begin{tabular}{|c|c|c|c|c|c|c|c|}
\hline \multirow[t]{2}{*}{ Year } & \multicolumn{3}{|c|}{ Number of seeds in a single ovary } & \multicolumn{3}{|c|}{ Position and rate $(\%)$ of ovule abortion } & \multirow[t]{2}{*}{ Mean $(\%)$} \\
\hline & $\begin{array}{l}\text { Total } \\
\text { number of } \\
\text { seeds }\end{array}$ & $\begin{array}{l}\text { Normal seeds } \\
\text { (mature seeds) }\end{array}$ & Abortion seeds & Upper part of the ovary & Middle part of the ovary & Lower part of the ovary & \\
\hline 2019 & $6-16$ & $0-8$ & $4-14$ & $66.25 \pm 3.20 \mathrm{~b}$ & $66.98 \pm 2.66 b$ & $77.08 \pm 1.65 \mathrm{a}$ & $69.14 \pm 1.41$ \\
\hline 2020 & $6-16$ & $1-8$ & $4-14$ & $70.86 \pm 2.813 b$ & $83.33 \pm 2.484 \mathrm{a}$ & $78.59 \pm 1.523 \mathrm{a}$ & $74.01 \pm 1.06$ \\
\hline 2021 & $8-23$ & $0-7$ & $6-17$ & $74.90 \pm 1.93 \mathrm{a}$ & $71.65 \pm 1.76 a$ & $78.95 \pm 1.64 \mathrm{a}$ & $77.88 \pm 8.52$ \\
\hline
\end{tabular}

Different lowercase letters indicate significant difference at the 0.05 level $(P<0.05)$

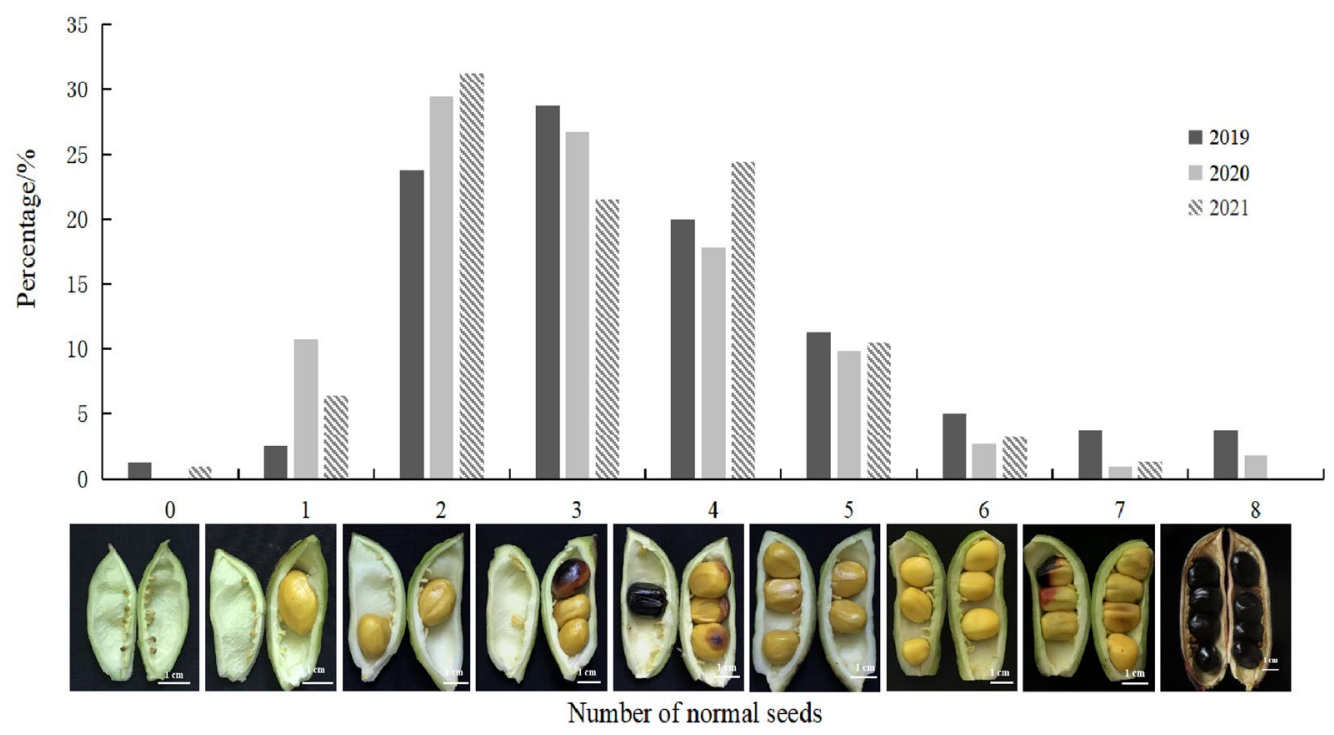

Fig. 8 Distribution of the number of normal seeds in Paeonia ludlowii ovaries 
the abortion rate was the highest in the middle part of the ovary $(83.33 \%)$, followed by the lower part $(78.59 \%)$ and the upper part $(70.86 \%)$. These results showed that there was no specific position for seed abortion in the ovary of $P$. ludlowii, and that seed abortion was random.Moreover, in 2021, the abortion rate in the lower part of the ovary was the highest (78.95\%) and the abortion rates in the upper and middle parts were $74.90 \%$ and $71.65 \%$, respectively.

\section{Discussion}

\section{Characteristics of the carpel and embryo sac of P. ludlowii}

The carpels are plant reproductive organs, and ovary development (ovule development and embryo sac formation) and stigma and style formation are particularly important for fertilization (Gao et al. 2019; Bedinger et al. 2016). The carpels of tree peonies are composed of the ovary, style, and stigma. Zhao and Lian (2002) found that the stigma of $P$. ludlowii curled at an angle of approximately $90^{\circ}$. However, in this study, most of the stigmas curled into a ring at an angle of $360^{\circ}$ or nearly $360^{\circ}$. The results of this study were slightly different from those of previous studies; this could be because, in order to adapt to the environment and to meet the needs of pollination, the stigma had undergone a certain degree of evolution, which enlarged the pollen surface. In addition, the electron microscopy structure of the stigma showed that the stigma surface of $P$. ludlowii is covered with a large number of papillae, which also helps the stigma to accept many pollen grains.

The style of $P$. ludlowii is hollow, with a canal in the center. As in lily and camellia, which have hollow styles, the channel is surrounded by a layer of glandular secretory cells, also known as channel cells (Gao et al. 2019; Hu et al. 1982; Zhang 2020). The style is the only way that the pollen tubes can enter the ovary. In plants with style channels, pollen tubes mainly grow along the surface of the channel cells and then enter the ovary (Gao et al. 2015a).

The ovules of $P$. ludlowii are inverted, with a double integument, thick nucellus, and polygonum-type embryo sac. The basic structure is the same as that of other peonies (Cheng and Aoki 1999; Wang et al. 2010). The embryo sac of $P$. ludlowii developed and matured earlier, with one synergistic cell degenerating at $12 \mathrm{~h}$ after flowering, and the embryo sac entered the fertilization state. Walters' (1962) research on $P$. californica revealed that each ovule had 1-4 embryo sacs, and the phenomenon of multiple embryo sac development has also been found in the ovules of $P$. rockii (Cheng and Aoki 1999). However, only one embryo sac was observed in one ovule inseveral of $P$. ludlowii samples during our experiment. Wang et al. (2010) observed one embryo sac in P. delavayi, Further, Vinogradova and Zhinkina (2020) indicated that only one embryo sac formed in $P$. veitchii and $P$. caucasica, and they assumed that callose participates in blocking the developmental signals to neighboring megasporocytes that further arrests their development.

\section{Characteristics of pollen tube growth in P. Iudlowii}

The completion time of pollen grain germination and pollen tube growth is $2-3 \mathrm{~h}$ in $P$. rockii (Cheng 1996). However, the pollen grains of $P$. ostii 'Feng Dan' germinate immediately after falling on the stigma and form pollen tube channels $1 \mathrm{~h}$ after pollination, and the pollen tubes enter the ovule and reach the embryo sac within $12-48 \mathrm{~h}$ after pollination (Chen 2020; Dong 2010; Fan et al. 2004). In 'High Noon' (a distant hybrid between subgroups in the Sect. Moutan), germination is not observed until 8-11 days after pollination, when the pollen tube enters the nucellus ( $\mathrm{He}$ and Cheng 2006). Here, the observation of $P$. ludlowii were similar to those of P. ostii 'Feng Dan', and the pollen tubes in P. ludlowii entered the embryo sac at 48-60 h after flowering. Pollen germination capacity and pollen tube growth rate in plant styles are affected by internal and external factors, such as the variety characteristics, nutritional conditions, temperature, light, and climate, as reported in some species and varieties (Dogterom et al. 2000; Lau and Stephenson 1994; Ruane 2008; Schlichting 1986; Tuell and Isaacs 2010). Thus, the germinated pollen tube takes a longer time to enter the embryo sac in $P$. ludlowii than in $P$. rockii due to varietal differences, planting conditions, and climatic conditions after pollination.

In angiosperms, the pollen tube enters the ovule in two ways, namely porogamy and chalazogamy ( $\mathrm{Li}$ and Gao 2008). When the pollen tube of $P$. ludlowii approached the ovule, it turned nearly $90^{\circ}$ and entered the micropyle. Therefore, the fertilization pattern of $P$. ludlowii is porogamy, as in Chrysanthemum grandiflorum and Camellia oleifera (Deng et al. 2010; Gao et al. 2015b). The double fertilization of $P$. ludlowii is consistent with that in P. rockii (Cheng 1996), indicating that double fertilization in $P$. ludlowii is normal. According to a report by Dong (2010), in P. ostii 'Feng Dan', two sperms enter the egg cell at the same time or near the secondary nucleus. However, we did not observe this phenomenon in P. ludlowii. Whether it was related to the experimental materials remains to be studied.

\section{Characteristics of double fertilization and development of embryo and endosperm in $P$. ludlowii}

The development of endoembryo and endosperm in the fertile ovule of $P$. ludlowii is similar to that in other tree peony species (Cave et al. 1961; Cheng and Aoki 1999; Dong 2010; 
Table 2 Initiation time of free nuclear proembryos and endosperm in Paeonia

\begin{tabular}{|c|c|c|c|c|}
\hline Plant species & Growing environment (location) & $\begin{array}{l}\text { Cellular time of proembryo } \\
\text { (days after flowering or pollina- } \\
\text { tion, day) }\end{array}$ & $\begin{array}{l}\text { Cellular time of endosperm } \\
\text { (days after flowering or pollina- } \\
\text { tion, day) }\end{array}$ & Source \\
\hline $\begin{array}{l}\text { P. californica } \\
\text { P. brownii }\end{array}$ & Wild (California, US) & $>12-14$ & $>12-14$ & Cave et al. (1961) \\
\hline P. lactiflora & Cultivated (Beijing, China) & $17-23$ & $>17-23$ & Mu and Wang (1985) \\
\hline P. rockii & Cultivated (Lanzhou, China) & 29 & 29 & Cheng (1996) \\
\hline P. ostii 'Feng Dan' & Cultivated (Shanghai, China) & 23 & 23 & Dong (2010) \\
\hline P. ludlowii & Cultivated (Luoyang, China) & 30 & 45 & This study \\
\hline
\end{tabular}

Mu and Wang, 1985), but the timing is significantly different (Table 2). This difference can be attributed to the plant species and environmental conditions, such as flowering and early embryo development temperatures.

\section{Ovule abortion and its characteristics in P. Iudlowii}

In seed plants, abortion can be divided into nonrandom and random abortion. The former refers to a certain regularity in the position of seed abortion in the fruit, as in Phaseolus coccineus (Rocha and Stephenson 1990), Robinia pseudoacacia (Susko 2006; Yuan et al. 2014), Caesalpinia gilliesii (Calviño 2014), Bauhinia ungulata (Mena-Alí and Rocha 2004), and Anagyris foetida (Valtueña et al. 2010). The latter means that the abortive seeds have no specific position in the fruit. Evidently, the abortion in P. ludlowii belongs to the latter.

The aborted ovules of $P$. ludlowii are of three types: abnormal pistils, sterile ovules, and embryo and endosperm abortions. The phenomenon of pistil abortion, such as abnormal pistils and sterile ovules, is common in nature (Hou et al. 2011; Wang 2006; Wetzstein et al. 2011). However, although pistil abortion exists, ovule abortion in P. ludlowii mainly involves embryo and endosperm abortions. According to the time, embryo and endosperm abortions in P. ludlowii could be divided into two types. (1) Early abortive, which occurred at 9-12 days after flowering and the aborted ovules stopped growing and were smaller than fertile ovules. The development of endosperm was abnormal, the free nucleus of the endosperm continued to degenerate, and the embryo sac became narrow. The number of abortive ovules in the ovary was more than $60 \%$, and all carpels had abortive ovules. (2) Medium-term abortive, which occurred at approximately 20 days after flowering. The volume of aborted ovules was slightly larger than that of other early aborted ovules and slightly smaller than that of fertile ovules. The free nuclei of the embryo and endosperm in the embryo sac began to degenerate. Based on the proportion of aborted ovules observed in each stage, the embryo and endosperm of $P$. ludlowii were mainly aborted in the early stage, that is, 9-14 days after flowering. This occurrence time was slightly different from the results of He and Cheng (2006), which might be related to various characteristics of the plant including different pollination and fertilization times.

Several factors besides species characteristics and resource constraints affect plant embryo abortion (Brookes et al. 2008; Florez-Rueda et al. 2016; Nakamura 1988; Teixeira et al. 2006). These include sibling competition (Ganeshaiah and Uma Shaanker 1988; Jerry and Carol 2015), poor pollination and fertilization (Miyajima et al. 2003; Shen et al. 2018; Xie et al. 2019), endosperm abortion (Sun et al. 2009; Pan et al. 2011), abnormal hormone metabolism (DeBruin et al. 2018; Daniela et al. 2020a, b; Okamoto and Omori 1991), and nutritional supply imbalance (Ji et al. 2019; Shen et al. 2020). P. ludlowii is self-compatible (Li et al. 1996; Tang et al. 2021), and the pollen fertility and germination rate of $P$. ludlowii are high (Jia et al. 2021). In this study, there was no abnormality in the process of pollination and fertilization, therefore the factor of poor pollination and fertilization could be excluded. During flowering and fruiting, the axillary buds on the flowering branches of $P$. ludlowii sprouted into the secondary branches, and the apical buds on the secondary branches differentiated (Yuan et al. 2021). Thus, the fruit development period coincided with the secondary branch growth period and the apical bud differentiation period. Consequently, the nutrients should be balanced and distributed among the three, and this may be one of the causes of ovule abortion. In addition, during the early and middle stages of embryo and endosperm abortion, the endosperm degenerated first, while the embryo remained intact, possibly because the embryo growth and differentiation mainly depend on the endosperm. As an important source of nutrients for embryo development, the endosperm can store nutrients, such as starch, lipids, and proteins (Gehring et al. 2004; Lopes and Larkins 1993; Stephen et al. 2008). When the endosperm degenerated, the embryo lacked nutrients and was aborted. In conclusion, the reasons for ovule abortion in $P$. ludlowii are complex and influenced by several factors. The findings of this study expand our understanding of the source and characteristics 
of ovule abortion, and the specific factors of ovule abortion could be an important future research direction focus.

Based on the renewal status of $P$. ludlowii forests, many naturally renewing seedlings were also found under suitable habitat conditions (Hong et al. 2017), indicating that this species does not have serious reproductive obstacles in the short term. The self-breeding rate of $P$. ludlowii is as high as 34.26-60\% (Li et al. 1996; Tang et al. 2021), which provides some long-term reproductive protection and evolutionary potential for the species to adapt to a changing environment. However, whether inbreeding will cause genetic load that would lead to low competitiveness and abortion of some ovules remains to be investigated.

In recent years, with the development of local tourism and transportation, airports, new hotels, and roads have been built in Nyingchi, thereby causing disturbance and changes to the distribution areas of $P$. ludlowii. Presently, we are faced with the issue of harmonizing local economic development, arising from human activities in wild habitats, with the protection of endangered species, which should be urgently addressed.

Acknowledgements We would like to thank Prof. Fenglan Li and Prof. Jin Cheng for assistance with morphological image identification. We thank Editage (http://www.editage.cn) for English language editing.

Author contributions TQC and TY conceived and designed research. TQC, MYX and YMJ conducted experiments. TQC analyzed data. TQC wrote the manuscript. All authors read and approved the manuscript.

Funding This work is supported by the Special Fund for Beijing Common Construction Project, the World-Class Discipline Construction and Characteristic Development Guidance Funds for Beijing Forestry University (2019XKJS0324).

Data availability The authors declare that all data supporting the findings of this study are provided in full in the results section of this paper.

\section{Declarations}

Conflict of interest The authors declare no competing or financial interests.

Open Access This article is licensed under a Creative Commons Attribution 4.0 International License, which permits use, sharing, adaptation, distribution and reproduction in any medium or format, as long as you give appropriate credit to the original author(s) and the source, provide a link to the Creative Commons licence, and indicate if changes were made. The images or other third party material in this article are included in the article's Creative Commons licence, unless indicated otherwise in a credit line to the material. If material is not included in the article's Creative Commons licence and your intended use is not permitted by statutory regulation or exceeds the permitted use, you will need to obtain permission directly from the copyright holder. To view a copy of this licence, visit http://creativecommons.org/licenses/by/4.0/.

\section{References}

Arathi HS, Ganeshaiah KN, Shaanker RU, Hegde SG (1999) Seed abortion in Pongamia pinnata (Fabaceae). Am J Bot 86:659-662. https://doi.org/10.2307/2656574

Bedinger PA, Broz AK, Tovar-Mendez A, McClure B (2016) Pollenpistil interactions and their role in mate selection. Plant Physiol 173:79-90. https://doi.org/10.1104/pp.16.01286

Brookes RH, Jesson LK, Burd M (2008) A test of simultaneous resource and pollen limitation in Stylidium armeria. New Physiol 179:557-565. https://doi.org/10.1111/j.1469-8137.2008.02453.x

Burd M (1998) "Excess" flower production and selective fruit abortion: a model of potential benefits. Ecology 79:2123-2132. https://doi. org/10.1890/0012-9658(1998)079[2123:EFPASF]2.0.CO;2

Calviño A (2014) Effects of ovule and seed abortion on brood size and fruit costs in the leguminous shrub Caesalpinia gilliesii (Wall. ex Hook.) D. Dietr Acta Bot Bras 28:59-67. https://doi.org/10.1590/ S0102-33062014000100006

Cave MS, Armott HJ, Cook SA (1961) Embryogeny in the California peonies with reference to their taxonomic position. Am J Bot 48:397-404. https://doi.org/10.2307/2439332

Chen M (2020) Study on the development characteristics of Paeonia ostii 'Feng Dan' seeds and its yield components. Dissertation, Yangzhou University

Cheng FY (1996) Study on the sexual reproduction process of Paeonia rockii. Dissertation, Beijing Forester University

Cheng FY, Aoki N (1999) Development of ovule and embryo sac in blotched tree peony (Paeonia rockii). Bull Fac Life Env Sci Shimane Univ 4:13-20

Cheng FY, Li JJ, Yu L (1998) Exportation of Chinese tree peonies (Mudan) and their developments in other countries II: wild species. J Northwest Normal Univ (nat Sci). https://doi.org/10. 16783/j.cnki.nwnuz.1998.03.027

Cheng YQ, Zhang HD, Liu JF (2015) Improvement of lignified style softening method in Hazelnut. Jilin Normal Univ J (nat Sci Ed). https://doi.org/10.16862/j.cnki.issn1674-3873.2015.03.029

Cui YN, Zhang SS, Zeng XL, Zhao F, Li Q (2019) Photosynthetic characteristics of Paeonia ludlowii variant material in Lhasa. Chin Agric Sci Bull 35:60-64

Daniela BT, Maria DG, Pablo T, Miguel APA (2020a) On the way to ovules: the hormonal regulation of ovule development. Crit Rev Plant Sci 39:431-456. https://doi.org/10.1080/07352689.2020. 1820203

Daniela BT, Carrera E, Baños J, Julia PR, Omar RR, Tornero P, Alonso JM, Isabel LD, Gómez MD, Miguel APA (2020b) Regulation of ovule initiation by gibberellins and brassinosteroids in tomato and Arabidopsis: two plant species, two molecular mechanisms. Plant J 102:1026-1041. https://doi.org/10.1111/tpj.14684

DeBruin JL, Hemphill B, Schussler JR (2018) Silk development and kernel set in maize as related to nitrogen stress. Crop Sci 58:25812592. https://doi.org/10.2135/cropsci2018.03.0160

Deng YM, Teng NJ, Chen SM, Chen FD, Guan ZY, Song AP, Chang QS (2010) Reproductive barriers in the intergeneric hybridization between Chrysanthemum grandiflorum (Ramat.) Kitam. and Ajania przewalskii Poljak. (Asteraceae). Euphytica 174:41-50. https://doi.org/10.1007/s10681-009-0113-3

Dogterom MH, Winston ML, Mukai A (2000) Effect of pollen load size and source (self, outcross) on seed and fruit production in highbush blueberry cv. "Bluecrop" (Vaccinium corymbosum; Ericaceae). Am J Bot 87:1584-1591. https://doi.org/10.2307/ 2656734

Dong ZL (2010) Studies on the reproductive biology of Paeonia ostii 'Feng Dan'. Dissertation, Beijing Forester University

Fan BY, Gao SP, Jiang XN, Wang ZY (2004) Preliminary study on the time of the form of pollen tube pathway of peony (Paeonia 
suffruticosa Andr.). J Henan Agric Sci 05:51-52. https://doi.org/ 10.3969/j.issn.1004-3268.2004.05.016

Florez-Rueda AM, Paris M, Schmidt A, Widmer A, Grossniklaus U, Städler T (2016) Genomic imprinting in the endosperm is systematically perturbed in abortive hybrid tomato seeds. Mol Biol Evol 33:2935-2946. https://doi.org/10.1093/molbev/msw175

Ganeshaiah KN, Uma Shaanker R (1988) Seed abortion in wind-dispersed pods of Dalbergia sissoo: maternal regulation or sibling rivalry? Oecologia 77:135-139. https://doi.org/10.1007/BF003 80936

Gao C, Yuan DY, Yang Y, Wang BF, Liu DM, Zou F (2015a) Pollen tube growth and double fertilization in Camellia oleifera. Jam Soc Hortic Sci 140:12-18. https://doi.org/10.21273/JASHS.140.1.12

Gao C, Yuan DY, Yang Y, Wang BF, Liu DM, ZouF TXF (2015b) Anatomical characteristics of self-incompatibility in Camellia oleifera. Sci Silvae Sinicae 51(60-68):30. https://doi.org/10.11707/j. 1001-7488.20150208

Gao C, Yang R, Guo QQ, Yuan DY (2019) Microstructure and ultrastructure characteristics of stigma and style of Camellia oleifera. For Res 32:1-7. https://doi.org/10.13275/j.cnki.lykxyj.2019.01. 001

Gehring M, Choi Y, Fischer RL (2004) Imprinting and seed development. Plant Cell 16(suppl1):S203-S213. https://doi.org/10.1105/ tpc.017988

Hao HP, He Z, Li H, Shi L, Tang YD (2014) Effect of root length on epicotyl dormancy release in seeds of Paeonia ludlowii, Tibetan peony. Ann Bot 113:443-452. https://doi.org/10.1093/aob/mct273

He GM, Cheng FY (2006) Morphological observation of sexual reproduction abortion in 'High Noon' tree peony. Acta Hortic Sinica 33:660-663. https://doi.org/10.3321/j.issn:0513-353X.2006.03. 044

He Z (2008) Seed dormancy and germination characteristics of Paeonia ludlowii, an endangered plant endemic to China. Dissertation, IBCAS. https://d.wanfangdata.com.cn/thesis/ChJUaGVzaX NOZXdTMjAyMTA1MTkSCFkxNjI4OTgw Ggh6dDM2aH M1eg\%3D\%3D. Accessed June 2008

Hong DY (1997) Paeonia (Paeoniaceae) in Xizang (Tibet). Mo Bot Gard Press 7:156-161. https://doi.org/10.2307/3392188

Hong DY, Pan KY (2005) Notes on taxonomy of Paeonia sect. Moutan DC (Paeoniaceae). Acta Phytotaxon Sinica 43:169-177

Hong DY, Zhou SL, He XJ, Yuan JH, Zhang YL, Cheng FY, Zeng XL, Wang Y, Zhang XX (2017) Current status of wild tree peony species with special reference to conservation. Biodivers Sci 25:781-793. https://doi.org/10.17520/biods.2017129

Hou JH, Gao ZH, Zhang Z, Chen SM, Ando T, Zhang JY, Wang XW (2011) Isolation and characterization of an AGAMOUS homologue PmAG from the Japanese apricot (Prunus mume Sieb. et Zucc.). Plant Mol Biol Rep 29:473-480. https://doi.org/10.1007/ s11105-010-0248-3

Hu SY, Zhu C, Xu LY (1982) The structure of the canal cell in the style of Lilium regale. Acta Bot Sinica 24(05):395-402, 493-496. https://mall.cnki.net/magazine/Article/ZWXB198205000.htm

Jerry MB, Carol CB (2015) Pollen (microgametophyte) competition: an assessment of its significance in the evolution of flowering plant diversity, with particular reference to seed germination. Seed Sci Res 25(1):1-11. https://doi.org/10.1017/S0960258515000033

Ji W, Guo RR, Wang JB, Jiao XB, Yan Z, Chang QX, Dong ZG, Wang YJ (2019) Grey correlation analysis of physiological and biochemical factors in embryo abortion of seedless grape. Acta Hortic Sinica 46:1473-1485. https://doi.org/10.16420/j.issn.0513-353x. 2019-0011

Jia WQ, Wang YL, Guo YZ, Wang Z, Qi Q, Yan SN, Liu HC, He SL (2021) Characterization of pollen germination and storage of Paeonia ludlowii. Sci Silvae Sinicae 57:82-92. https://doi.org/10. 11707/j.1001-7488.20210209
Kho YO, Baër J (1968) Observing pollen tubes by means of fluorescence. Euphytica 17:298-302. https://doi.org/10.1007/BF000 21224

Lau TC, Stephenson AG (1994) Effects of soil phosphorus on pollen production, pollen size, pollen phosphorus content, and the ability to sire seeds in Cucurbita pepo (Cucurbitaceae). Sex Plant Reprod 7:215-220. https://doi.org/10.1007/BF00232740

Li R (2005) Studies on protection and utilization of the Wild TreePeony in China. Dissertation, Gansu Agricultural University

Li FL, Gao SM (2008) Plant biology. China Forestry Ture Press, Beijing

Li J, Wang ZH (2019) Nutrients, fatty acid composition and antioxidant activity of the flowers and seed oils in wild populations of Paeonia ludlowii. Emir J Food Agric 31:206-213. https://doi.org/10.9755/ ejfa.2019.v31.i3.1922

Li JJ, He LX, Chen DZ, Chen FH, Cheng FY (1996) Preliminary report on the introduction test of Paeonia ludlowii in Tibel. Collection of plant introduction and domestication. Science Press, Beijing, pp 105-110

Li HE, Guo QQ, Zheng WL (2018) Characterization of the complete chloroplast genomes of two sister species of Paeonia: genome structure and evolution. Conserv Genet Resour 10:209-212. https://doi.org/10.1007/s12686-017-0800-7

Li ZQ, Jiao YT, Zhang C, Dou MR, Weng K, Wang YJ, Xu Y (2021) $V v H D Z 28$ positively regulate salicylic acid biosynthesis during seed abortion in Thompson seedless. Plant Biotechnol J. https:// doi.org/10.1111/PBI.13596

Lopes MA, Larkins BA (1993) Endosperm origin, development, and function. Plant Cell 5:1383-1399. https://doi.org/10.2307/38697 90

Lu YZ, Zhang EH, Hong MS, Yin X, Cai H, Yuan L, Yuan F, Li LQ, Zhao KT, Lan XZ (2020) Analysis of endophytic and rhizosphere bacterial diversity and function in the endangered plant Paeonia ludlowii. Arch Microbiol 202:1717-1728. https://doi.org/10.1007/ s00203-020-01882-3

Lu YZ, Zhang CQ, Yu BX, Zhang EH, Quan H, Yin X, Cai H, Yuan F, Li LQ, Xu YJ et al (2021) The seed oil of Paeonia ludlowii ameliorates A $\beta 25$-35-induced Alzheimer's disease in rats. Food Sci Nutr 9:2402-2413. https://doi.org/10.1002/FSN3.2102

Luo YB, Pei YL, Pan KY, Hong DY (1998) A study on pollination biology of Paeonia suffruticosa subsp. spontanea (paeoniaceae). Acta Phytotaxon Sinica 02:3-5

Mena-Alí JI, Rocha O (2004) Effect of ovule position within the pod on the probability of seed production in Bauhinia ungulata (Fabaceae). Ann Bot 95:449-455. https://doi.org/10.1093/aob/ mci044

Meyer KM, Soldaat LL, Auge H, Thulke HH (2014) Adaptive and selective seed abortion reveals complex conditional decision making in plants. Am Nat 183:376-383. https://doi.org/10.1086/ 675063

Miyajima D, Karito I, Fujisawa R (2003) Ovule and seed abortion in Japanese morning glory (Ipomoea nil (L.) Roth.). J Jpn Soc Hortic Sci 72:402-408. https://doi.org/10.2503/jjshs.72.402

Mu XJ, Wang FX (1985) The early development of embryo and endosperm of Paeonia lactiflora. J Integr Plant Biol 27(01):7-12, 115-116. https://mall.cnki.net/magazine/Article/ZWXB198501 001.htm

Nakamura RR (1988) Seed abortion and seed size variation within fruits of Phaseolus vulgaris: pollen donor and resource limitation effects. Am J Bot 75:1003-1010. https://doi.org/10.2307/2443768

National Forestry and Grassland Administration of China (2021) List of National Key Protected Wild Plants. http://www.forestry.gov. cn/main/3954/20210908/163949170374051.html 
Ni SW (2009) Introduction and ex-situ conservation of Paeonia delavayi, Paeonia lutea, Paeonia ludlowii. Dissertation, Beijing Forestry University

Okamoto G, Omori N (1991) Effect of the levels of minerals, phytohormones and pistil extracts on in vitro ovule development and pollen tube growth in excised grape pistils. J Jpn Soc Hortic Sci 60:521-529. https://doi.org/10.2503/jjshs.60.521

Oneal E, Willis JH, Franks RG (2016) Disruption of endosperm development is a major cause of hybrid seed inviability between Mimulus guttatus and Mimulus nudatus. New Physiol 210:1107-1120. https://doi.org/10.1111/nph.13842

Pan KY, Wen J, Luo YB, Zhou SL (1999) Formation of microspores and development of male gametes in Paeonia jishanensis, with an analysis of factors of endangerment of this entity. Acta Phytotaxon Sin 37:3-5. https://doi.org/10.1088/0256-307X/16/12/025

Pan XJ, Li SY, Zhang WE, Liu CH (2011) Observing microstructure of embryo development and abortion of ruby seedless grape. Seed 30:66-67. https://doi.org/10.3969/j.issn.1001-4705.2011.11.017

Rocha OJ, Stephenson AG (1990) Effect of ovule position on seed production, seed weight, and progeny performance in Phaseolus coccineus L. (Leguminosae). Am J Bot 10:1320-1329. https:// doi.org/10.2307/2444592

Ruane LG (2008) Ecological factors affect pollen-pistil compatibility and hybridization dynamics. Available from Biological Science Collection; ProQuest Dissertations \& Theses Global A\&I: The Sciences and Engineering Collection (304602627)

Satoki S, Tomomi K (2009) Overproduction and selective abortion of ovules based on the order of fertilization revisited. J Theor Biol 260:2519-2523. https://doi.org/10.1016/j.jtbi.2009.06.014

Schlichting CD (1986) Environmental stress reduces pollen quality in phlox: compounding the fitness deficit. Springer, New York

Shen S, Zhang L, Liang XG, Zhao X, Lin S, Qu LH, Liu YP, Gao Z, Ruan YL, Zhou SL (2018) Delayed pollination and low availability of assimilates are major factors causing maize kernel abortion. J Exp Bot 69:1599-1613. https://doi.org/10.1093/jxb/ery013

Shen S, Liang XG, Zhang L, Zhao X, Liu YP, Lin S, Gao Z, Wang P, Wang ZM, Zhou SL (2020) Intervening in sibling competition for assimilates by controlled pollination prevents seed abortion under postpollination drought in maize. Plant Cell Environ 43:903-919. https://doi.org/10.1111/pce.13704

Stephen GP (2008) Physiology of woody plants (3rd edn). Academic Press, New York

Sun B, Cao HN, He W, Gong YM, Zong CL (2009) Study on a embryo abortion stage of pseudothenocarpy seedless grape. Agric Sci J Yanbian Univ 31:159-164

Susko DJ (2006) Effect of ovule position on patterns of seed maturation and abortion in Robinia pseudoacacia (Fabaceae). Botany 84:1259-1265. https://doi.org/10.1139/b06-094

Tang Y, Yuan T, Chen TQ (2021) Flowering characteristics and breeding system of Paeonia ludlowii. Acta Bot Boreal Occident Sin 41:0782-0794. https://doi.org/10.7606/j.issn.1000-4025.2021. 05.0782

Teixeira SD, Pereira RAS, Ranga NT (2006) Components of fecundity and abortion in a tropical tree, Dahlstedtia pentaphylla (Leguminosae). Braz Arch Biol Techn 49:905-913

Tuell JK, Isaacs R (2010) Weather during bloom affects pollination and yield of highbush blueberry. J Econ Entomol 103:557-562. https://doi.org/10.1603/EC09387
Valtueña FJ, Ortega-Olivencia A, Rodríguez-Riaño T, López J (2010) Causes of low fruit and seed set in bird-pollinated Anagyris foetida (Leguminosae): pollen limitation and other extrinsic factors. Folia Geobot 45:77-94. https://doi.org/10.1007/s12224-009-9054-9

Vinogradova GY, Zhinkina NA (2020) Why does only one embryo sac develop in the Paeonia ovule with multiple archesporium? Plant Biol 23:267-274. https://doi.org/10.1111/PLB.13206

Walters JL (1962) Megasporogenesis and gametophyte selection in Paeonia californica. Am J Bot 49:787-794. https://doi.org/10. 2307/2439173

Wang Y, Li YH, Peng ZH (2010) Megasporogenesis, microsporogenesis and development of female and male gametophytes of Paeonia delavayi var. Lutea. J Northeast for Univ 38:62-65. https:// doi.org/10.13759/j.cnki.dlxb.2010.05.016

Wang YL (2006) Studies on biology of pollination fertilization and embryo aborted in Wuhexuegan (Citrus sinensis L. Osbeck). Dissertation, Fujian Agriculture and Forestry University

Wetzstein HY, Ravid N, Wilkins E, Martinelli AP (2011) A morphological and histological characterization of bisexual and male flower types in pomegranate. J Am Soc Hortic Sci 136:83-92. https://doi.org/10.21273/JASHS.136.2.83

Xie DR, Ma XS, Rahman MZ, Yang MC, Huang XM, Li JG, Wang HC (2019) Thermo-sensitive sterility and self-sterility underlie the partial seed abortion phenotype of Litchi chinensis. Sci Hortic 247:156-164. https://doi.org/10.1016/j.scienta.2018.11.083

Yang XL, Wang QJ, Lan XZ, Li CY (2007) Number dynamics of the endangered plant population of Paeonia ludlowii. Acta Ecol Sinica 03:1242-1247. https://doi.org/10.3321/j.issn:1000-0933. 2007.03.051

Yuan CQ, Sun YH, Li YF, Zhao KQ, Hu RY, Li Y (2014) Selection occurs within linear fruit and during the early stages of reproduction in Robinia pseudoacacia. BMC Evol Biol 14:53. https://doi. org/10.1186/1471-2148-14-53

Yuan T, Chen TQ, Tang Y (2021) Secondary branches development of Paeonia ludlowii. Acta Hortic Sinica 48:117-126. https://doi.org/ 10.16420/j.issn.0513-353x.2020-0171

Zhang Y (2020) Researches on pollination configuration of six Camellia oleifera varieties. Dissertation, Huazhong Agricultural University

Zhang CQ, Xu YJ, Lu YZ, Li LQ, Lan XZ, Zhong ZC (2020) Study on the fatty acids, aromatic compounds and shelf life of Paeonia ludlowii kernel oil. J Oleo Sci. https://doi.org/10.5650/jos.ess20084

Zhao MG (2002) The study on the development and transformation of the floral organs in the genus Paeonia Linn. Dissertation, Northwest Normal University

Zhao MG, Lian YS (2002) A comparative study on carpellary morphology character and ovary anatomy structure of sect. Moutan in Paeonia. J Northwest Normal Univ (nat Sci). https://doi.org/10. 16783/j.cnki.nwnuz.2002.01.021

Publisher's Note Springer Nature remains neutral with regard to jurisdictional claims in published maps and institutional affiliations. 